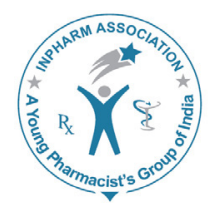

\title{
Inhibition of proteasome activity by the dietary flavonoid Quercetin associated with growth inhibition in cultured breast cancer cells and xenografts
}

\author{
Debasish Pradhan*, Rakesh Kumar Pradhan, Gitanjali Tripathy, \\ Shaktiprasad Pradhan
}

Department of Pharmaceutical Sciences, Utkal University, VaniVihar, Bhubaneswar, Odisha, India.

\begin{abstract}
Objective: To study the Inhibition of proteasome activity by the dietary flavonoid Quercetin associated with growth inhibition in cultured breast cancer cells and xenografts. Methods: MCF-7 breast cancer cell cultures and xenografts were treated with quercetin, carried out by following measurement of reduced cellular viability/proliferation, proteasome inhibition, and apoptosis induction. Inhibition of the proteasome was decided by levels of the proteasomal chymotrypsin-like activity, by target proteins, and by accumulation of proteasome target proteins in extracts of the treated cells or tumours. Apoptotic cell inhibition was measured by capase-3/caspase-7 activation, poly (ADP-ribose) polymerase cleavage, and immunohistochemistry for terminal nucleotidyl transferase. Results: This result is carried out for the first time by us that quercetin inhibits the proteasomal chymotrypsin-like activity and induces apoptosis not only in cultured MCF-7 cell lines but also in MCF-7 xenografts moreover, while quercetin has antibreast tumour activity and no toxicity was observed to the tested animals. Conclusion: We have shown that quercetin is an effective proteasome inhibitor in cultured breast cancer cells and in breast cancer xenografts. Furthermore, quercetin induces apoptotic cell death in human breast cancer cells and exhibits anticancer activities in tumours. The results suggest its potential benefits in breast cancer prevention and treatment.
\end{abstract}

Key words: Breast cancer, MCF-7, Proteasome activity, Quercetin, Xenografts.

\section{INTRODUCTION}

Consistent consumption of polyphenols has been related with decreased cancers and with tumour development treatment. ${ }^{1}$ The polyphenolic flavone quercetin is broadly distributed among fruits and vegetables, and quercetin

\begin{tabular}{|c|c|}
\hline \multicolumn{2}{|c|}{ Access this article online } \\
\hline Journal Sponsor & \multirow[b]{2}{*}{$\begin{array}{l}\text { Website: } \\
\text { www.jyoungpharm.org }\end{array}$} \\
\hline \multirow{2}{*}{ www.phcog net } & \\
\hline & $\begin{array}{l}\text { DOI: } \\
\text { 10.5530/jyp.2015.3.13 }\end{array}$ \\
\hline
\end{tabular}

has been indicated to have chemopreventive activities in a number of cancer models including those of lung cancer, ${ }^{2}$ skin cancer, ${ }^{3}$ cervical cancer, ${ }^{4}$ prostate cancer, ${ }^{5}$ and leukemia. ${ }^{6}$ The mechanism by which quercetin imparts its anticancer activities are varied and may possess activity through antiinflammation, ${ }^{7}$ free radical scavenging, ${ }^{8}$ and proteasome inhibitions. ' The eukaryotic proteasome is a large multicatalytic, multisubunit protease complex having three distinct activities, which are related with three different $\beta$ subunits, respevtively: chymotrypsin-like activity (with the $\beta 5$ subunit), trypsin-like activity (with the $\beta 2$ subunit), and peptidyl-glutamyl peptide-hydrolyzing-like (caspase-

\footnotetext{
*Address for correspondence:

Dr. Debasish Pradhan, Department of Pharmaceutical Sciences, Utkal University, VaniVihar, Bhubaneswar, Odisha, India.

E-mail :deba_udps@yahoo.co.in
} 


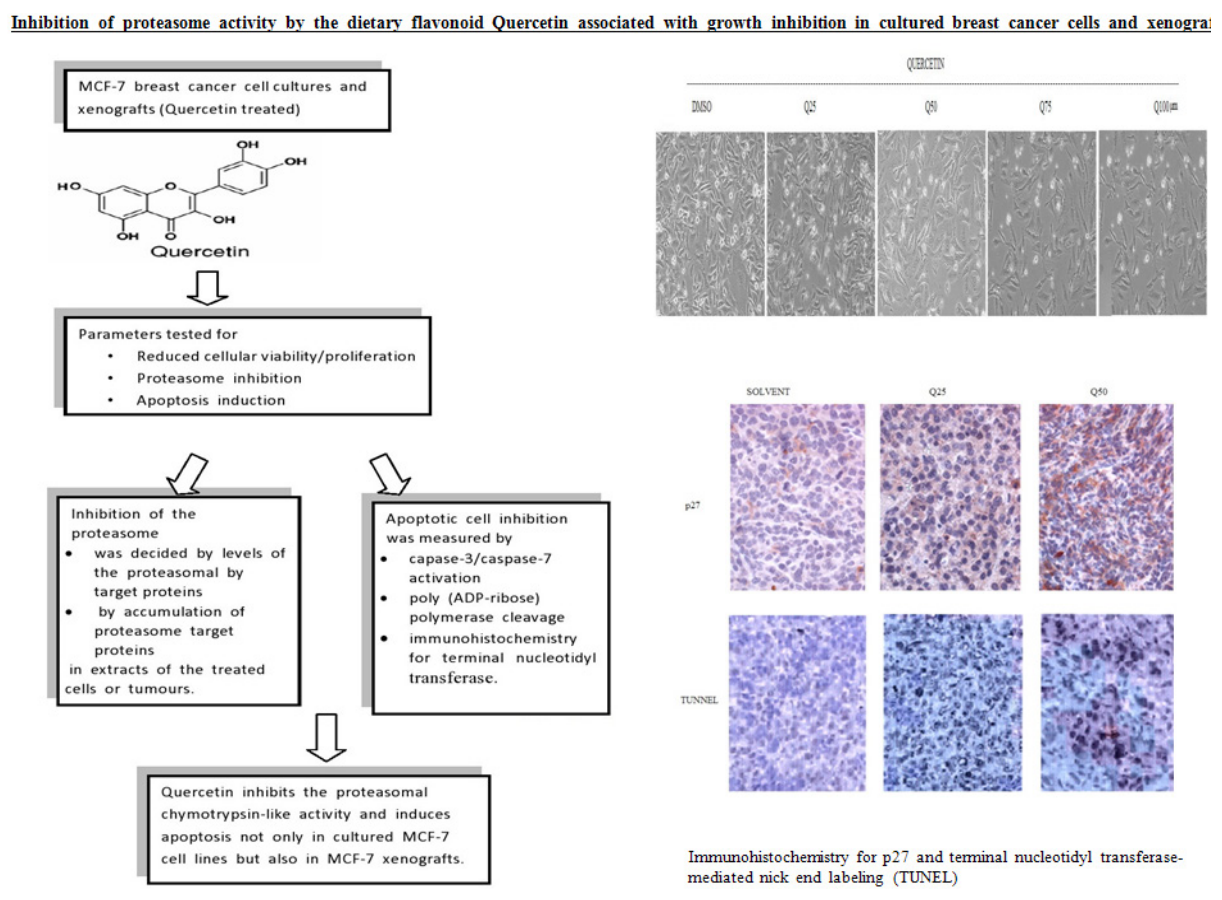

Graphical Abstract

like) activity (with the $\beta 1$ subunit). ${ }^{10}$ Chymotrypsin-like activity inhibition and not the trypsin-like activity of the proteasome has been associated with induction of tumour cell apoptosis. ${ }^{11}$ By inspecting a wide range of cell culture models, it has been discovered that proteasome inhibitors quickly induce tumour cell apoptosis, specifically initiate the cell death programme in cancer or oncogen-transfered cells, however not in normal or untransformed cells, and are capable to trigger apoptotic death in human cancer cells that are resistant to different anticancer agents. ${ }^{12}$

The most depicted proteasome inhibitor, PS-341, is a dipeptide boronic acid analog with the cell-death-inducing activity found in several tumour cell lines. ${ }^{13}$ The mechanism of action of PS-341 has been indicated to be Inhibition of the $\beta 5$-subunit and the $\beta 1$-subunit, with the $\beta 5$-subunit as the dominant cell-death impelling targets.

Since clinically accessible proteasome inhibitors are related with some toxicity, ${ }^{14}$ natural proteasome inhibitors with less or no toxicity are alluring potential anticancer agents. Quercetin potently inhibits the chymotrypsin-like activity of a purified 20s proteasome and 30s proteasome in cultured tumour leukemia cells. ${ }^{6}$ Proteasome inhibition drove to the accumulation of proteasome target proteins (such as I $x \mathrm{~b}$ and $\mathrm{Bax}$ ) and to subsequent induction of apoptosis in human leukemia cancer cells, as measured by initiation of caspases and cleavage of poly(ADP-ribose) polymerase (PARP). ${ }^{9}$
The chemopreventive impacts of quercetin are charized, ${ }^{15}$ and cytotoxic impacts in leukemia cells was observed.' Whether quercetin has potential antibreast cancer activity and whether it could target the breast cancer proteasome, nonetheless, remain unclear. In the current study, we provide proof that the proteasome-inhibitory activity of quercetin stretches out to breast cancer cells and tumours. Proteasome Inhibition, growth concealment, and apoptosis actuation were observed in cultured breast cancer MCF-7 cell lines treated with quercetin. Quercetin was harmless to ordinary cells ${ }^{6}$ and treatment of breast cancer bearing nude mice with quercetin was analyzed-resulting in tumour development inhibition and massive apoptosis incitement, related with proteasome inhibition in vivo. No clear toxicity to the tested animals was observed. The information suggest that quercetin acts as a natural proteasome inhibitor under physiological conditions. While prevention of cancer has been the predominant attribute to quercetin, our discoveries are characteristic of extraordinary potential for tumour treatment.

\section{MATERIALS AND METHODS}

\section{MATERIALS}

Quercetin, bisbenzimide Hoechst number 33258 stain, 3-[4,5-dimethyltiazol-2-yl]-2.5-diphenyl-tetrazolium bromide (MTT), dimethylsulfoxide (DMSO), cremophor and other chemicals were purchased from Sigma-Aldrich 
(Mumbai, India). RPMI 1640, penicillin, and streptomycin were acquired from Invitrogen (Mumbai,India). The fluorogenic peptide substrates Suc-LLVY-AMC (for the proteasomal chymotrypsin-like development) and N-acetyl-DEVD-AMC (for caspase-3/caspase-7 activity) were from Calbiochem (Pune, India). Mouse monoclonal antibody against human PARP was purchased from LAB Chemicals Pvt. Ltd. (Bhubaneswar, India). Mouse monoclonal antibodies against Bax (B9), ubiquitin (P4d1), goat polyclonal immunizer against actin (C-11), rabbit polyclonal neutralizing operators against $\mathrm{I} x \mathrm{~b} \alpha(\mathrm{C} 15)$, and discretionary antibodies were purchased from ICSCCB (Pune, India). The MCF-7 cell lines were obtained from NCCS Pune, India. The balancing operators of p27 for immunohistochemistry was from UDPS, Utkal University.

\section{Cell culture and cell extract preparation}

MCF-7 cell lines were grown in RPMI 1640 supplemented with 10\% fetal bovine serum, $100 \mathrm{u} / \mathrm{ml}$ Penicillin, and $100 \mu \mathrm{g} / \mathrm{ml}$ Streptomycin. Cells were grown at $37^{\circ} \mathrm{C}$ in a humidified incubator with an atmosphere of $5 \% \mathrm{CO}_{2}$. A whole cell extract was prepared. ${ }^{16}$ Briefly, MCF-7 breast cancer cells were grown to $60-70 \%$ confluency, and were treated with $25 \mu \mathrm{m}, 50 \mu \mathrm{m}, 75 \mu \mathrm{m}$, or $100 \mu \mathrm{m}$ quercetin or DMSO control (at a concentration measure to the volume used for the most highest concentration of quercetin or $\leq$ $0.1 \%$ ) for 24 hours. At the endpoint of the tests, cells were procured, washed twice with PBS and homogenized in a lysis buffer (50 mm Tris (ph 8.0), $5 \mathrm{~mm}$ ethylenediamine tetraacetic acid, $150 \mathrm{mM} \mathrm{NaCl}, 0.5 \% \mathrm{NP} 40)$. After 30 minutes of shaking at $4{ }^{\circ} \mathrm{C}$, the mixtures were centrifuged at $12,000 \times \mathrm{g}$ for 15 minutes and the supernatants were accumulated.

\section{Proteasomal chymotrypsin-like and caspase-3/ caspase- 7 activity assays}

Whole cell extracts $(10 \mu \mathrm{g})$ of cells treated with quercetin or tumour tissue extracts $(10 \mu \mathrm{g})$ from human breast tumour xenograft were incubated for 2.5 hours at $37^{\circ} \mathrm{C}$ in $100 \mu \mathrm{l}$ assay buffer $(50 \mathrm{mmol} / \mathrm{l}$ Tris-HCl, ph 7.5$)$ with $10 \mu \mathrm{mol} / 1$ fluorogenic substrate Suc-LLVY-AMC (for proteasomal chymotrypsin-like activity) or Ac-DEVDAMC (for caspase- $3 /$ caspase- 7 activity). ${ }^{17}$ After incubation, production of free hydrolyzed 7-amino-4-methylcoumarin (AMC) groups liberated by substrate hydrolysis was fluorometrically measured using a Victor 3 Multilabel Counter with an excitation channel of $380 \mathrm{~nm}$ and an emission channel of $460 \mathrm{~nm}$ (Mumbai, India).

\section{Cell viability/proliferation assay}

The MT'T measure, an index of cell viability and cell growth, was used to determine the effects of different compounds on MCF-7 breast cancer cells. Cells were plated in a 96-well plate and were ended upto 70-80\% confluence, followed by extension of each compound at the indicated concentration. After 24 hours of incubation at $37^{\circ} \mathrm{C}$, the MTT solution was replaced by $100 \mathrm{ml}$ DMSO. When the blue crystals were dissolved, the optical density (OD) was measured in a Wallac Victor3 TM multilabel plate reader (Perkin Elmer, USA) at a wavelength of $560 \mathrm{~nm}$. The formula used to evaluate the result is as follows:

Inhibition of cell proliferation $(\%)=(\mathrm{OD}$ of the experimental samples/OD of the control) x 100\%.18

All assays were done in triplicate in three independent tests, and the mean value for each test was calculated. The results are indicated as the mean \pm standard deviation and are expressed as percentage of the control, which was $100 \%$.

\section{Cellular morphology analysis}

A Zeiss Axiovert 25 microscope (Pune, India) was used for all microscopic imaging with either phase contrast for cellular morphology. ${ }^{19}$ Cells collected as a detached fraction, were washed with ice cold PBS and then fixed in ethanol for $1 \mathrm{hr}$. Thereafter cells were washed with ice cold PBS and were stained with $50 \mu \mathrm{M}$ Hoechst and kept in the dark at $4^{\circ} \mathrm{C}$ for 30 minutes and then visualized using fluorescence microscopy. Punctate and bright staining, or granular and bright staining nuclei were considered apoptotic.

\section{Western blot analysis}

The entire cell extracts or tumour lysates were separated by SDS-PAGE gel and were transferred to a nitrocellulose membrane. Western blot analysis was performed using specific antibodies against ubiquitin, $\mathrm{Bax}, \mathrm{I} x \mathrm{~b} \alpha$, PARP or $\beta$-actin, followed by visualization utilizing the enhanced chemiluminescence reagent. ${ }^{19}$

\section{Human breast tumour Xenograft experiments}

Female athymic nude mice, age 5 weeks, were purchased from NCCS (Pune, India) and were housed 12 hour day and night exposure by the IAEC (UDPS, Utkal University). Human breast cancer MCF- 7 cell lines $\left(5 \times 10^{6}\right)$ suspended in $0.1 \mathrm{ml}$ serum free RPMI 1640 were inoculated subcutaneously in both flanks of every mouse (four mice every group). 


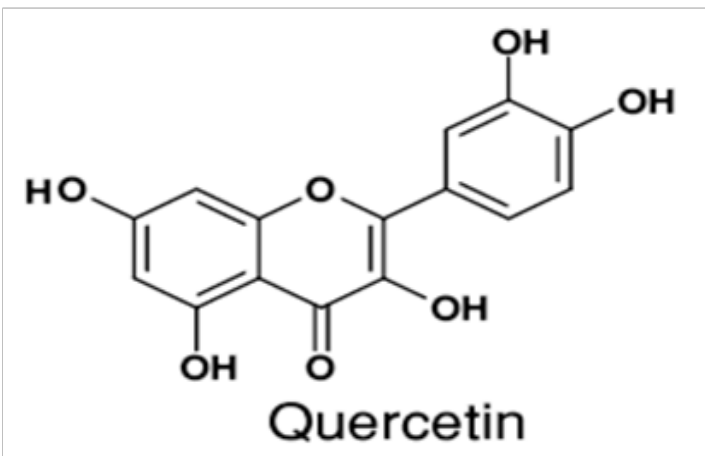

Figure 1a: Structure of Quercetin

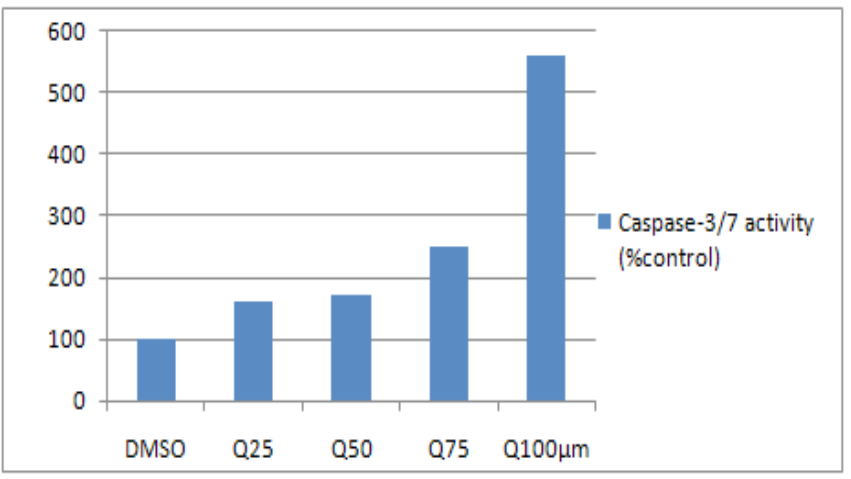

Figure 1c: Activation of caspase-3/caspase-7 activity in MCF-7 cell lines treated with indicated concentrations of quercetin for 24 hours, followed by measuring the caspase-3/caspase-7 activity in cell extracts

When the tumours were sizes of $\sim 120 \mathrm{~mm}^{3}$ on average, the mice were grouped randomly $(n=4)$ and were treated by subcutaneously infusion with 25 or $50 \mathrm{mg} / \mathrm{kg}$ quercetin daily, or vehicle (10\% DMSO, 40\% Cremophor/ethanol (3:1) and 50\% PBS). The tumour size was measured each other day utilizing calipers, and the tumour volumes were calculated to standard formula: length $\times$ width $^{2} / 2$. Mice were sacrificed after 29 days of treatment. Then the tumours were collected and photograph was taken and the tumour tissues were used for multiple assay.

Terminal nucleotidyl transferase-mediated nick end labeling and immunohistochemistry using tumour tissue samples

The terminal nucleotidyl transferase-mediated nick end labeling (TUNEL) assay utilizing an in situ apoptosis detection kit, and immunostaining of p27 were performed. ${ }^{19}$ The proteasomal chymotrypsin-like activity assay and

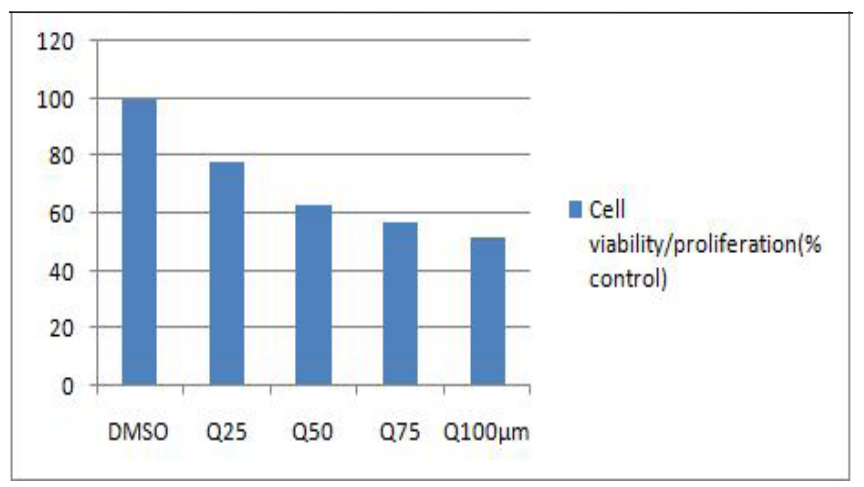

Figure 1b: Viability/proliferation-inhibitory effect of quercetin on the MCF-7 breast cancer cell line. MCF-7 cell lines were treated for 24 hours with increasing concentrations of quercetin followed by a 3-[4,5-dimethylthiazol-2-yl]-2,5-diphenyl-tetrazolium bromide assay

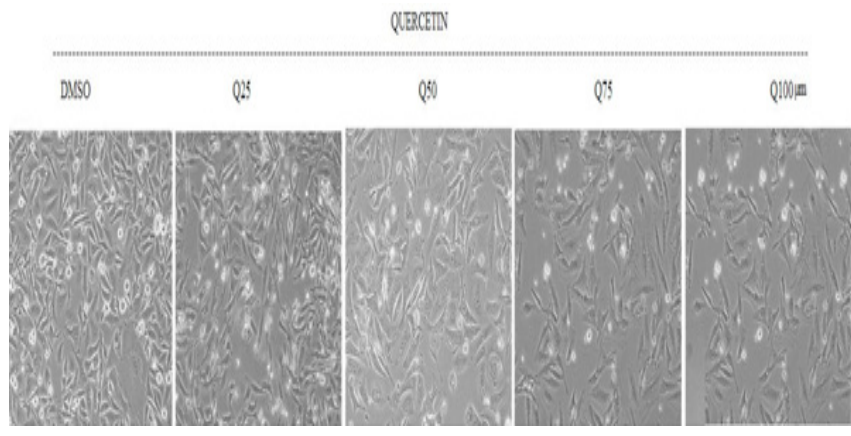

Figure $1 \mathrm{~d}$ : Examination for morphological changes visualized by phase-contrast imaging ( $100 \times$ magnification). Three independent experiments were performed and each individual experiment was tested in triplicate ((b) and (c)). Similar results were found with all experiments and the data shown represent one experiment; bars, standard deviation. DMSO, dimethylsulfoxide

western blot analysis utilizing animal tumour samples were performed as above utilizing cultured breast cancer cells.

\section{Statistical analysis}

To evaluate the difference between a treatment and control, the Student test was applied. The level of significance was set at $\mathrm{P}<0.05$.

\section{RESULTS}

Quercetin could inhibit cell viability/proliferation and could initiate caspase-3/caspase-7 activity of MCF-7 breast cancer cells in a dose dependant manner. In the present study, we first examined the impacts of quercetin (Figure 1a) in a dose dependent manner $(25,50,75$, or $100 \mu \mathrm{m})$ on the highly metastatic and invasive human breast cancer cell line, MCF-7 cell lines. The results of an MTT assay shows that quercetin inhibited cell viability, and potential proliferation, 


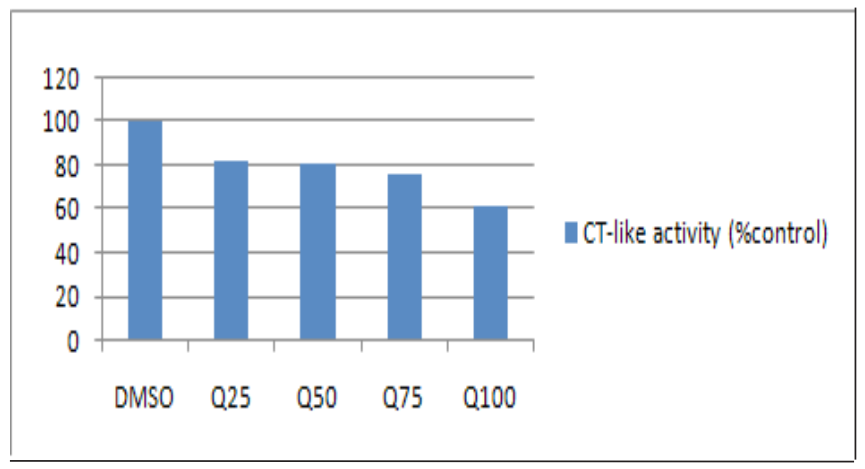

Figure 2a: Inhibition of proteasomal chymotrypsin (CT)-like activity by quercetin in MCF-7 cell lines. Cells were treated with various concentrations of quercetin for 24 hours, were harvested and were analyzed for the proteasomal chymotrypsin-like activity in cell extracts

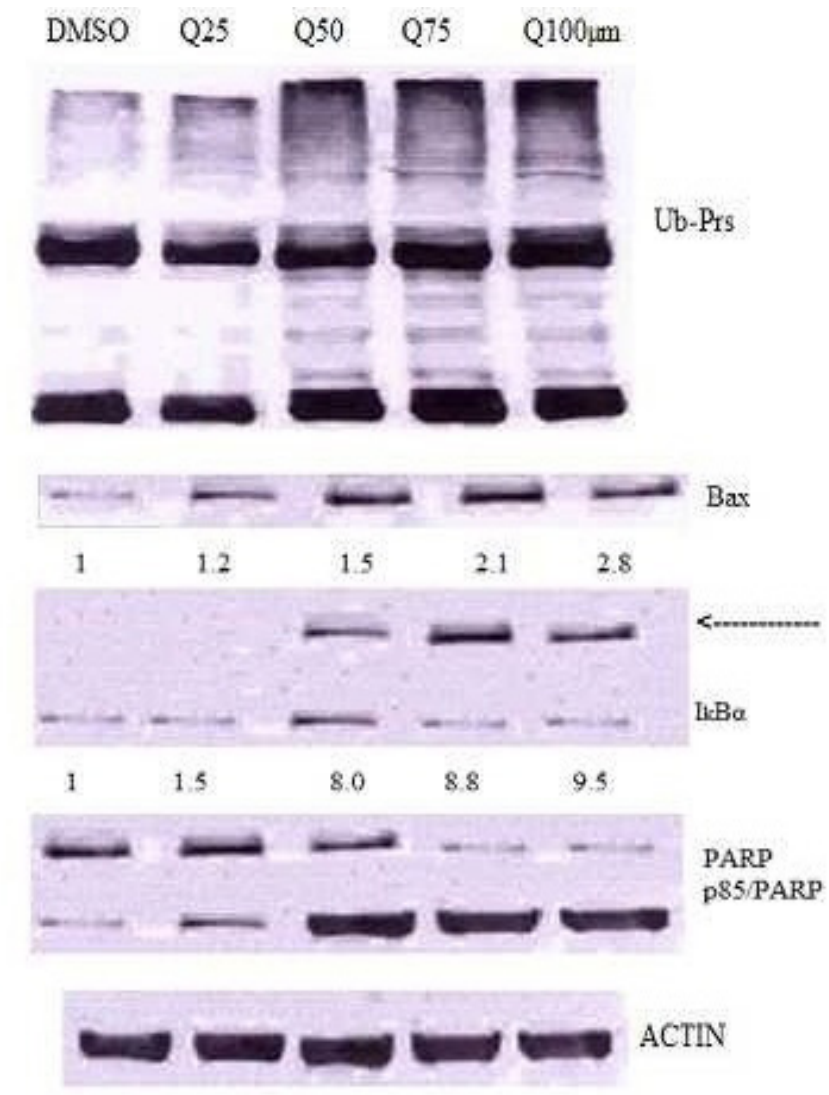

Figure 2b: Western bolt analysis for accumulation of ubiquitinated proteins (Ub-prs), Bax, IKb $\alpha$ and poly(ADP-ribose) polymerase (PARP) in the above prepared cell extract $s$ after 72 hours of treatment. Arrow ubiquitinated IKb $\alpha$ (p56). Three Independent experiments were performed and each individual experiment was tested in triplicate. Similar results were found with all experiments and data shown represent one experiment; bars, standard deviation. DMSO, dimethylsuldoxide. The number under each band of the western bolt indicates a quantitative analysis by densitometry. Quantitative number for IKb $\alpha$ include both bands of intact IKb $\alpha$ ( $p 37$ ) and ubiquitinated IKb $\alpha$ (p56)

after 24 hours of treatment in a dose dependent manner (Figure 1b). Treatment with $25 \mu \mathrm{m}, 50 \mu \mathrm{m}, 75 \mu \mathrm{m}$ and 100 $\mu \mathrm{m}$ quercetin inhibited cell viability/proliferation by $12 \%$, $27 \%, 42 \%$, and $49 \%$ respectively compared with DMSO control (Figure 1b). Besides, dose dependent caspase-3/ caspase- 7 activation was observed in the same test with a about five-fold increment in the cells treated at the highest concentration (Figure 1c). Also, morphological changes were observed after increasing dosages of quercetin in the same test (Figure 1d). Cells became elongated, losing their characteristic morphology and possibly cellular stress as compared with the DMSO (Figure 1d).

Quercetin can inhibit the chymotrypsin-like proteasome 
activity in leukemia Jurkat T cells. ${ }^{6}$ We hence speculated that quercetin could likewise target the tumour cellular proteasome in MCF-7 cell lines. To determine whether the reduced cell viability/proliferation by quercetin was due to its proteasome-inhibitory activity, MCF-7 cell lines were treated with $25 \mu \mathrm{m}, 50 \mu \mathrm{m}, 75 \mu \mathrm{m}$, or $100 \mu \mathrm{m}$ quercetin for 24 hours. After treatment, proteins were extracted and were used to measure the proteasome Inhibition by the fluorogenic proteasomal chymotrypsin-like activity assay and by western blot analysis. The proteasomal chymotrypsin-like activity was inhibited by $17 \%, 20 \%, 29 \%$, and $40 \%$ in the cells treated with $25 \mu \mathrm{m}, 50 \mu \mathrm{m}, 75 \mu \mathrm{m}$, and $100 \mu \mathrm{m}$ quercetin, respectively (Figure 2a). Western blot analysis showed an aggregation of ubiquitinated proteins (indicated by the increased intensity of the protein smear compared with the DMSO control) and the proteasome target protein Bax, most prevalently in cells exposed to the highest concentrations (Figure $2 \mathrm{~b}$ ).

Inhibition of the proteasomal chymotrypsin-like activity, yet not trypsin-like activity, has been indicated to be associaed with apoptosis incitement in cancer cells. ${ }^{11}$ To identify whether the proteasomal Inhibition is associated with apoptosis incitement, the presence of sliced PARP was analyzed. Apoptosis-specific sliced PARP was detected in cells treated with $50 \mu \mathrm{m}$ quercetin and higher concentrations (Figure 2b). These results show that quercetin is capable to inhibit the proteasomal chymotrypsin-like activity, resulting in apoptosis induction in human breast cancer MCF-7 cell lines.

Quercetin inhibits the development of human breast tumour xenografts, associated with proteasome inhibition and apoptosis incitement in vivo. After we demonstrated that quercetin could inhibit proteasomal activity and induce apoptosis in cultured breast cancer cells (Figures 1 and 2 ), we then determined whether quercetin could apply antitumour activity and whether that activity is related

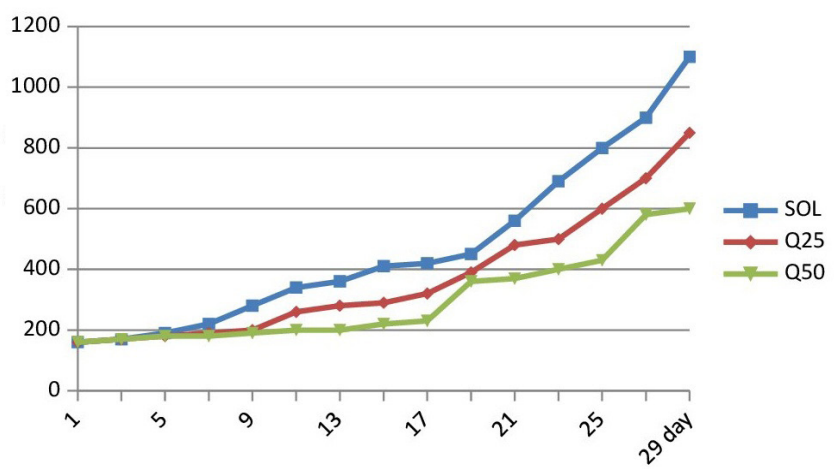

Figure 3a: Inhibition of MCF-7 tumor growth by quercetin with proteasome inhibition and apoptosis induction. Breast cancer MCF-7 cell lines $\left(5 \times 10^{6}\right)$ were implanted subcutaneously in 5-week-old female athymic nude mice. When the tumours reach at a discernable size $(\sim 120$ $\mathrm{mm}^{3}$ on average), the mice were treated subcutaneously with either the vehicle control or with 25 or $50 \mathrm{mg} /$ $\mathrm{kg}$ quercetin every day. Significant tumour development Inhibition by quercetin was observed after 29 days of treatment, demonstrating that quercetin has antitumour activity (Figure 3a). Control tumours developed to an normal size of 1,077 $\pm 114 \mathrm{~mm}^{3}$, while $25 \mathrm{mg} / \mathrm{kg}$ quercetintreated tumours developed to $842 \pm 71 \mathrm{~mm}^{3}$ and $50 \mathrm{mg} /$ $\mathrm{kg}$ quercetin-treated tumours developed to $622 \pm 66 \mathrm{~mm}^{3}$. This compares to $22 \%$ development Inhibition in the 25 $\mathrm{mg} / \mathrm{kg}$ quercetin-treated tumours $(\mathrm{P}<0.05$; Figure $3 \mathrm{a})$ and to $43 \%$ development Inhibition in the $50 \mathrm{mg} / \mathrm{kg}$ quercetintreated tumours $(\mathrm{P}<0.01$; Figure $3 \mathrm{a})$. We monitored the body weight of mice from every group, and the average body weight on the last day of treatment was $26.8 \mathrm{~g}, 26.5$ $\mathrm{g}$ and $26.3 \mathrm{~g}$ from the mice treated with the solvent, with $25 \mathrm{mg} / \mathrm{kg}$ quercetin, or with $50 \mathrm{mg} / \mathrm{kg}$ quercetin, separately. The data of the body weight proposed that there was no toxicity of quercetin.

\section{DISCUSSION}

Chemotherapy and radiotherapy have a critical part as single modalities for cancer treatment; on the other hand, they generally have limited effectiveness in the treatment of solid human tumours that often get to be drug resistant and are accompanied by severe drug related side effects. ${ }^{20}$ In an attempt to enhance conventional treatments, the proteasome has become an increasingly important molecular target.

The antitumour and chemosensitizing properties of the proteasome inhibitor PS-341 are well documented. ${ }^{21}$

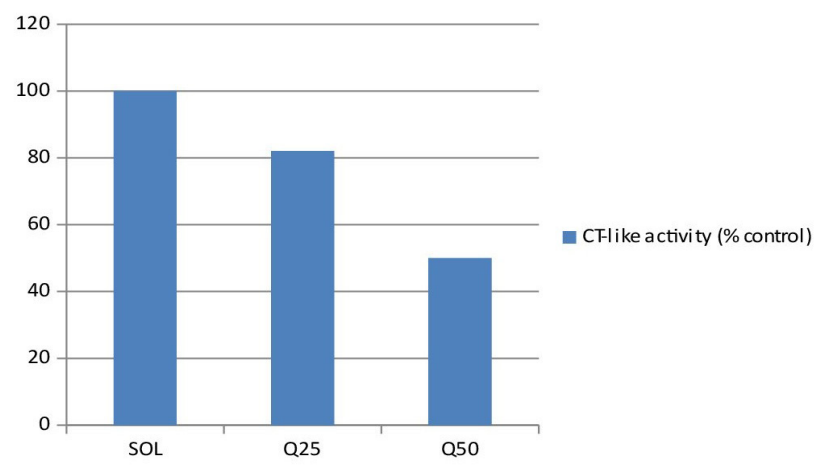

Figure 3b: Proteasomal chymotrypsin (CT)-like activity measured in the tumor samples

Journal of Young Pharmacists Vol 7 • Issue $3 \bullet$ Jul-Sep 2015 

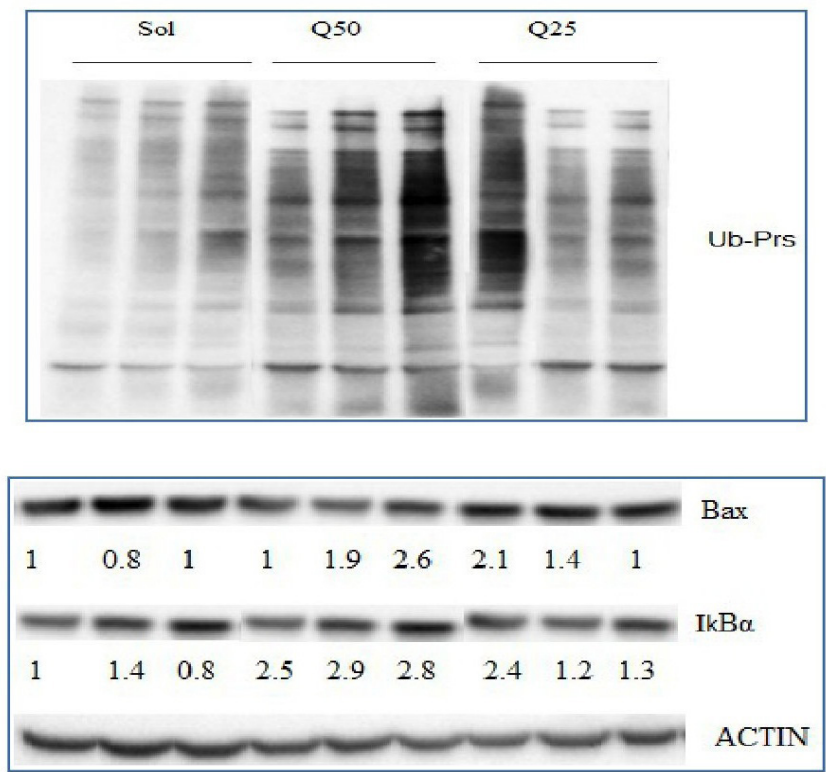

Figure 3c: Western bolt analysis for accumulation of ubiquitinated proteins (Ub-prs), Bax, IKb $\alpha$ and actin presented three representative individual tumor samples from each group of mice

Toxicity from bortezomib, however, has started an interest for recognizing nontoxic natural proteasome inhibitors such as the flavonoid quercetin that could potentially serve as nontoxic therapeutic and chemopreventive methodologies. Quercetin and other flavonoids were demonstrated to have proteasome-inhibitory action in human tumour cells, yet had little to no effect on typical, nontransformed cells.

We examined the effectiveness of quercetin in a breast cancer model utilizing human MCF-7 cell lines. After 24 hours, quercetin treatment inhibited breast cancer cell viability/ proliferation by half with the highest concentration (Figure 1b). Quercetin is capable to inhibit the chymotrypsin-like activity of a purified 20 s proteasome. ${ }^{6}$ We therefore estimated that the decreased cell viability or possibly reduced proliferation was due in large part to quercetin's proteasomal inhibitory activity. To test this hypothesis, MCF-7 cell lines were treated for 24 hours with quercetin, were gathered and lysed, and the cell extracts were examined for their chymotrypsin-like activity and by western blot analysis. At the highest concentration, proteasome activity was inhibited by approximately $40 \%$ (Figure 2a) and accumulation levels of ubiquitinated proteins, Bax and ubiquitinated $\mathrm{I} \chi \mathrm{b} \alpha$ were observed (Figure $2 \mathrm{~b}$ ). It is likely that an extended treatment in this in vitro model would give even more striking information.

To guarantee that the obvious proteasome inhibition

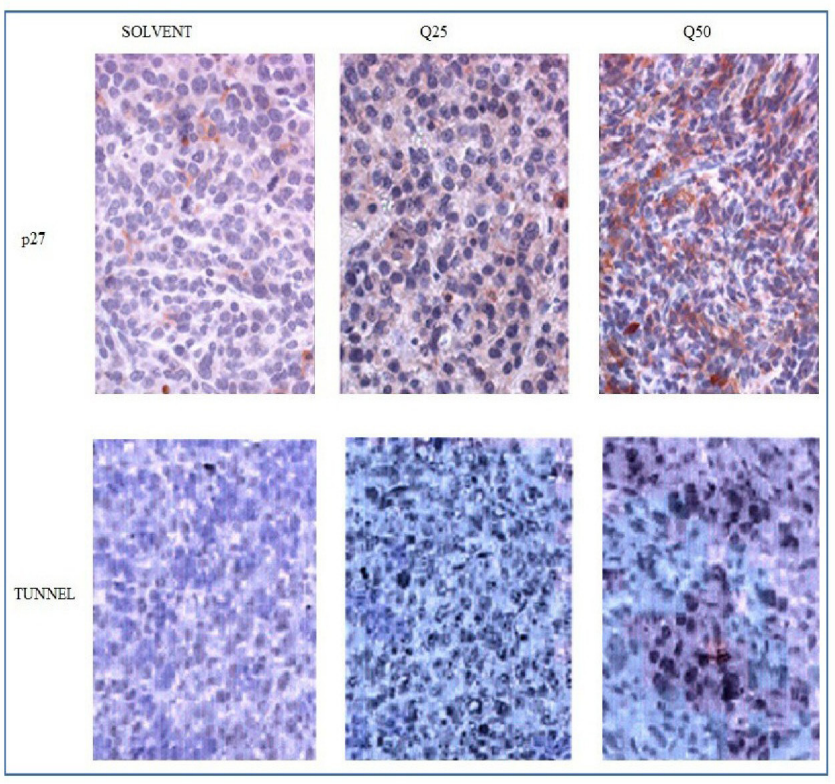

Figure 3d: Immunohistochemistry for p27 and terminal nucleotidyl transferase-mediated nick end labeling (TUNNEL). Data points, mean tumor volume in experimental group containing four mice, bars, standard deviation. Number under each band of the western blot indicates a quantitative analysis by densitometry compared with the loading control of actin

by quercetin treatment would lead to the induction of apoptosis, we analyzed the morphological changes, the event of activated caspase-3/caspase- 7 activity and, at last, the production of the sliced PARP fragments. MCF-7 cell lines exposed to quercetin showed changes in cellular morphology that might demonstrate a cellular stress (Figure 1d). A true measure of apoptosis in quercetin-treated cells was observed by caspase-3/caspase- 7 activation and sliced PARP most noticeably after treatment with the highest concentration of quercetin (Figures $1 \mathrm{c}$ and $2 \mathrm{~b}$ ).

Since the in vitro findings in this epithelial cancer model were so promosing, we then inspected the effects of quercetin treatment in a mouse model. Quercetin has been demonstrated to have growth inhibitory effects associated with cell-cycle regulation in nude mice bearing prostate cancer tumours. ${ }^{22}$ In our current study, treatment with quercetin resulted in prominent inhibition of proteasomal chymotrypsin-like activity (Figure 3b), accumulation of proteasome target proteins (thats $\mathrm{Bax}$ ), and induction of apoptosis in tumours (Figure $3 \mathrm{c}$ and $3 \mathrm{~d}$ ). Associated with the observed proteasome Inhibition and apoptosis actuation, significant tumour development Inhibition $(\sim 43 \%)$ by quercetin at the highest concentration was observed in this breast tumour model (Figure 3a).

In the present work we have demonstrated that quercetin, at moderately high dosages, exhibits no toxicity in an 
animal model while exerting proteasome-inhibitory and development inhibitory effects both in vitro and in vivo. This finding is of specific significance for future studies, which might incorporate the conveyance of quercetin in mix with other natural mixes or as a sensitising agent to conventional cancer therapeutics. In reality, a recent study proposed that quercetin might sensitise leukemia cells, prostate cancer cells, and colon cancer cells by inducing the expression of death receptor 5 , which, in combination with exogenous tumour necrosis factor related apoptosis-inducing ligand, acts synergistically to induce apoptosis while having no effect on ordinary cells. ${ }^{23}$ The evidence from these studies recommends that quercetin has great potential to be further developed as a cancer therapeutic.

The concentrations of quercetin used to treat cultured breast cancer cells and used as a part of the animal model is most likely higher than those found in the blood of people consuming dietary quercetin. The dose for quercetin in this mouse model, however, seemed to be well tolerated. During the 29-day treatment, there was no severe toxicity observed. More definite microscopic and macroscopic pathologic studies are needed to definitively record the lack of toxicity when quercetin is used at these concentrations.

\section{CONCLUSION}

The criticalness of the proteasome in the pathologic state of cancer and the potential for quercetin and other flavonoids as characteristic inhibitors of the proteasome might give a practical modality for the avoidance and treatment of some cancers. The findings reported in the present article demonstrate that quercetin seems to be a guaranteeing, novel anticancer agent, and one of its mechanism of action includes targeting on the tumour cellular proteasome and inducing apoptotic cell death. Utilizing an innocuous natural product or its prodrug as a chemosensitizer might lowers the toxicity and boost the effectiveness of current chemotherapeutics. Future analysis of quercetin in a combinational regimen might illustrate expanded effectiveness of this novel agent in additional cancer models.

\section{ABBREVIATIONS}

AMC: $\quad$ 7-amino-4-methylcoumarin;

DMSO: dimethylsulfoxide;

MT'T: 3-[4,5-dimethylthiazol-2-yl]-2,5diphenyl-tetrazolium bromide;

PARP: poly(ADP-ribose) polymerase;

PBS: $\quad$ phosphate-buffered saline;

TUNEL: Terminal nucleotidyl transferasemediated nick end labeling.

\section{CONFLICTS OF INTEREST}

The authors declare that they have no conflicts of Interest.

\section{ACKNOWLEDGEMENTS}

This work is partially supported by research grants from the DST, New-Delhi. The authors thank HOD, UDPS for his kind cooperation and assistance with experimental data acquisition. The authors are also grateful to National Centre for Cell Science (NCCS, PUNE, INDIA) for providing MCF-7 cancer cell lines.

\section{Highlights of Paper}

Quercetin inhibits proteasome activity associated with breast cancer cells and xenografts.

Quercetin inhibits the proteasomal chymotrypsin-like activity and induces apoptosis in cultured MCF-7 cell lines and MCF-7 xenografts. Quercetin has anti breast tumour activity and no toxicity in animals.

\section{Author Profile}

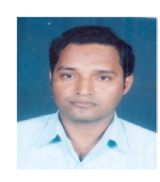

Dr. Debasish Pradhan is Sr. Faculty in Pharmacology at University Department of Pharmaceutical Sciences, Utkal University, Bhubaneswar, Odisha. His research interests are in the field of organization designs that maximize innovative patents. Currently he is a member of International Society of Ethno pharmacology; Institutional Animal Ethical Committee, UDPS, Utkal University; ISTE, Orissa branch; O.R/L.M.-70 APTI.

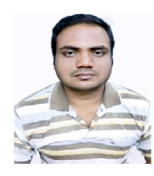

Mr. Rakesh Kumar Pradhan is a Master Degree holder in Pharmacy from University Department of Pharmaceutical Sciences, Utkal University, Bhubaneswar, Odisha. 


\section{REFERENCES}

1. Aggarwal BB, Shishodia S. Molecular targets of dietary agents for prevention and therapy of cancer. Biochem Pharmacol 2006; 71(10): 1397-1421.

2. Zheng SY, Li Y, Jiang D, Zhao J, Ge JF. Anticancer effect and apoptosis induction by quercetin in the human lung cancer cell line A-549. Mol Med Rep. 2012 Mar; 5(3): 822-6.

3. Bhatia N, Agarwal C, Agarwal R. Differential responses of skin cancer-chemopreventive agents silibinin, quercetin, and epigallocatechin 3-gallate on mitogenic signalling and cell cycle regulators in human epidermoid carcinoma A431 cells. Pub Med Nutr Cancer. 2001; 39(2): 292-9.

4. Huang LQ, Zhang W, Yang Y, Tao L. Effects and its mechanism of quercetin on cervical cancer HeLa cells. Pub Med. 2009 Jun; 44(6): 436-9.

5. Wang P, Vadgama JV, Said JW, Magyar CE, Doan N, Heber D, et al. Enhanced inhibition of prostate cancer xenograft tumor growth by combining quercetin and green tea. J Nutr Biochem. 2014 Jan; 25(1): 73-80.

6. Chen D, Daniel KG, Chen MS, Kuhn DJ, Landis-Piwowar KR, Dou QP. Dietary flavonoids as proteasome inhibitors and apoptosis inducers in human leukemia cells. Biochem Pharmacol 2005; 69(10): 1421-32.

7. Choi JS, Choi YJ, Park SH, Kang JS, Kang YH. Flavones mitigate tumour necrosis factor-alpha-induced adhesion molecule upregulation in cultured human endothelial cells: role of nuclear factor-kappa B. J Nutr. 2004; 134(1): 1013-19.

8. Sim GS, Lee BC, Cho HS, Lee JW, Kim JH, Lee DH, et al. Structure activity relationship of antioxidative property of flavonoids and inhibitory effect on matrix metalloproteinase activity in UVAirradiated human dermal fibroblast. Arch Pharm Res. 2007; 30(3): 290-8.

9. Chen D, Chen MS, Cui QC, Yang H, Dou QP. Structureproteasome-inhibitory activity relationships of dietary flavonoids in human cancer cells. Front Biosci. 2007; 12(1): 1935-45.

10. Groll M, Ditzel L, Lowe J, Stock D, Bochtler M, Bartunik HD, et al. Structure of $20 \mathrm{~S}$ proteasome from yeast at $2.4 \mathrm{~A}$ resolution. Nature 1997; 386(1): 463-71.

11. Pradhan D, Tripathy G, Patanaik S. Anticancer activity of L Acidissima Linn(Rutaceae) fruit extracts on Human Breast cancr cell lines; TJPR. 2012; 13(3): 413-9.

12. $\mathrm{Ma} \mathrm{MH}$, Yang $\mathrm{HH}$, Parker $\mathrm{K}$, Manyak S, Friedman JM, Altamirano $\mathrm{C}$, et al. The proteasome inhibitor PS-341 markedly enhances sensitivity of multiple myeloma tumour cells to chemotherapeutic agents. Clin Cancer Res 2003; 9(1): 1136-44.

13. Hideshima T, Richardson $P$, Chauhan $D$, Palombella VJ, Elliott PJ, Adams $\mathrm{J}$, et al. The proteasome inhibitor PS-341 inhibits growth, induces apoptosis, and overcomes drug resistance in human multiple myeloma cells. Cancer Res. 2001; 61(7): 3071-6.

14. Adams J. Potential for proteasome inhibition in the treatment of cancer. Drug Discov Today 2003; 8(7): 307-15.

15. Sharmila G, Bhat FA, Arunkumar R, Elumalai $P$, Raja Singh $P$, Senthilkumar $\mathrm{K}$, et al. Chemopreventive effect of quercetin, a natural dietary flavonoid on prostate cancer in in vivo model. Clin Nutr. 2014 Aug; 33(4): 718-26.

16. Anu B, Dou QP. Cleavage of retinoblastoma protein during apoptosis: an interleukin 1 beta-converting enzyme-like protease as candidate. Cancer Res 1996, 56(1): 438-42.

17. Nam S, Smith DM, Dou QP. Ester bond-containing tea polyphenols potently inhibit proteasome activity in vitro and in vivo. J Biol Chem 2001; 276(1): 13322-30.

18. Chen D, Peng F, Cui QC, Daniel KG, Orlu S, Liu J, et al. Inhibition of prostate cancer cellular proteasome activity by a pyrrolidine dithiocarbamate-copper complex is associated with suppression of proliferation and induction of apoptosis. Front Biosci. 2005; 10(2): 2932-9.

19. Chen D, Cui QC, Yang H, Dou QP. Disulfiram, a clinically used anti-alcoholism drug and copper-binding agent, induces apoptotic cell death in breast cancer cultures and xenografts via inhibition of the proteasome activity. Cancer Res. 2006; 66(21): 10425-3.

20. Jhanwar YS, Divgi C. Current status of therapy of solid tumours. J Nucl Med. 2005; 46(Suppl 1): 141S-S.

21. Landis-Piwowar KR, Milacic V, Chen D, Yang H, Zhao Y, Chan TH, et al. The proteasome as a potential target for novel anticancer drugs and chemosensitizers. Drug Resist Updat. 2006; 9(1): 263-73.

22. Di Chen, Kristin R, Landis-Piwowar Marina S, Chen Q, Ping Dou. Inhibition of proteasome activity by the dietary flavonoid apigenin is associated with growth inhibition in cultured breast cancer cells and xenografts. Breast Cancer Research 2007; 9(6): R80.

23. Su-Yu Chien, Yao-Chung Wu, Jing-Gung Chung, Jai-Sing Yang, Hsu-Feng Lu, Mei-Fen Tsou, et al. Quercetin-induced apoptosis acts through mitochondrial and caspase-3-dependent pathways in human breast cancer MDA-MB-231 cells. Hum Exp Toxicol 2009 28(6): 493-503. 